\title{
"Quién hace tanta bulla". Puntuaciones políticas de la voz y la escucha en la poesía latinoamericana
}

\section{"Quién hace tanta bulla". Voicing and listening political punctuations in Latin American poetry}

\section{Ana Porrúa \\ porruana@gmail.com \\ Universidad Nacional de Mar del Plata - CONICET, Argentina}

\section{Recepción: 09 Junio 2020}

Aprobación: 29 Septiembre 2020

Publicación: 06 Noviembre 2020

Cita sugerida: Porrúa, A. (2020). "Quién hace tanta bulla". Puntuaciones políticas de la voz y la escucha en la poesía latinoamericana. Orbis Tertius, 25(30), e166. https://doi.org/10.24215/18517811e166

\begin{abstract}
Resumen: Se abordará la cuestión de la voz y la escucha en algunos textos o escenas de la poesía latinoamericana del siglo XIX y, con mayor énfasis, del XX y el XXI. Se analizarán las delimitaciones y concomitancias entre la voz/logos y el ruido. Luego se focalizarán algunas constituciones históricas y culturales de la voz y el oído, a partir de la idea de resonancia y de escucha crítica, así como también del efecto de la puntuación sobre las hablas que propone nuevos enlaces entre oralidad y escritura.
\end{abstract}

Palabras clave: Voz, Escucha, Poesía Latinoamericana, Puntuación.

\begin{abstract}
In this article, the issue of voicing and listening in certain texts or scenes in Latin American poetry from the nineteenth century, and most especially twentieth and twenty-first centuries, will be discussed. Delimitations and concomitances between voice-logos and noise will be drawn. Certain historical and cultural constitutions of voice and hearing will be dealt with from the idea of resonance and critical listening, as well as the effect of punctuation on speech, which proposes new links between orality and writing.
\end{abstract}

Keywords: Voice, Listening, Latin American Poetry, Punctuation.

\section{Opus}

Nos proponemos leer la cuestión de la voz teniendo en cuenta que desde el poema o en la escucha de una puesta en voz o performance pueden relevarse nuevas distribuciones de lo decible, de la voz dividida en términos estéticos, de la distinción entre lo legible o lo escuchable y el ruido. ${ }^{1}$ En este sentido trabajaremos con corpus históricos, aunque no cronológicos; retomaremos textos y escenas a partir de cortes que agrupan heterogeneidades y que ponen en primer plano el conflicto que a veces se espectaculariza como lucha entre lo escuchable y lo que no participa de esa esfera, y se despliega también como modulación de la voz en tanto redistribuye tonos, espacios, hablas y escritura. ${ }^{2}$ La pregunta sobre quién tiene la voz en el poema, en este sentido, debe abrirse a las formas de esa voz (ya sea inscripta en la escritura, ya sea en un proceso de puesta en voz por parte del poeta o de un intérprete), pero también al enlace entre poesía y sonido en general que podría cifrarse como interrogación sobre aquello que suena en el poema y en tanto articulación de un arriba 
y un abajo, de un adentro y un afuera que, cada vez, aparece como puntuación de la historia, de la cultura y como nueva distribución o variación de lo escuchable.

En el principio, podríamos decir está el que pregunta. Trilce (1949 [1922]) de César Vallejo abre performáticamente con estos versos: "Quién hace tanta bulla y ni deja/testar las islas que van quedando". Alguien quiere testar y no puede hacerlo porque hay un ruido externo, una bulla. Ese alguien está innominado y la pregunta envía a una escena de pedido de palabra, marca un inicio, un íncipit dramático. El poema sigue así:

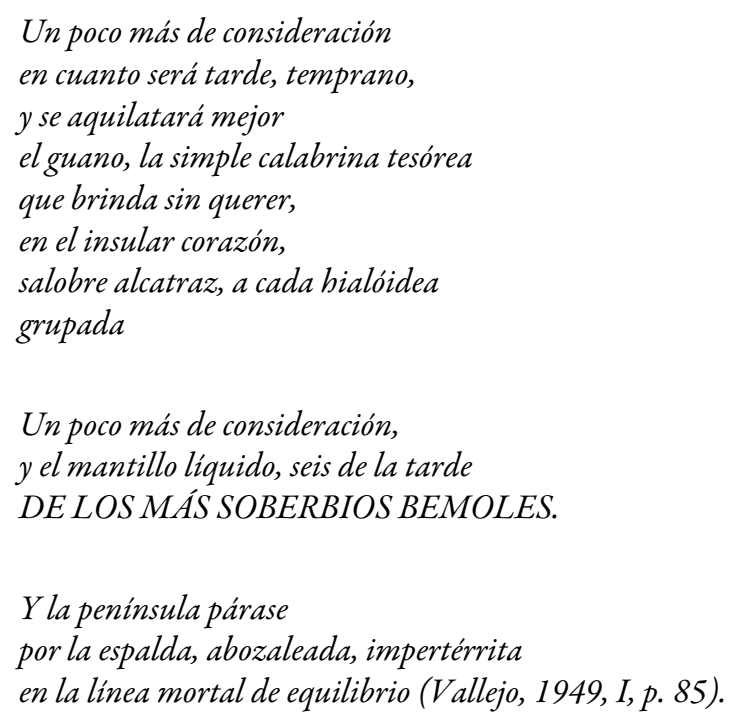

El que solicita la atención "argumenta" (es el tono del verso, su entonación explicativa, asertiva, lo que lo acerca al argumento): y aquí interesa, en todo caso, que en esa argumentación aparezca no ya lo innominado sino, en primer plano, una lengua nueva que tampoco podría adecuarse a la del testimonio (hablar de las islas guaneras, de la historia ¿de su país, de la conquista?). No se puede testar por el ruido, pero quien pide la palabra no dona otra cosa que sonidos, palabras sonoras: calabrina, tesórea, hialóidea, abozaleada.

La crítica ha tendido a pensar Trilce a partir de sus poemas más experimentales y, además, a leer esa experimentación en términos de ruptura, incluso de ruptura gramatical. ${ }^{3}$ Pero podría pensarse este primer poema de Trilce a partir de la constatación de una imposibilidad de decir que delinea implícitamente, en la pregunta y en el pedido de consideración, un espacio público o al menos una escena con oyentes que están inmersos en un rumor, una bulla, o la producen. Es decir, podría pensarse este poema de Trilce-y en realidad todo el libro- desde el sonido y como error/ fallo de la voz. ${ }^{4}$ No es que no pueda testimoniar; en la continuidad del poema queda claro que lo que importa no es el testimonio, el poema político que dice una verdad, que da voz a los que no tienen voz. El gesto contrario sería el de Canto general (2000 [1950]) de Pablo Neruda, que sí parte de la figura de dar la voz y esa voz, cuando hablan los mineros, los indios, los oprimidos de la historia, en ese largo itinere por América Latina y su historia puntuada por acontecimientos (batallas, huelgas, revoluciones), es la del poeta: "Yo vengo a hablar por vuestra boca muerta.", y más adelante: "Apegadme los cuerpos como imanes./ Acudid a mis venas y a mi boca./ Hablad por mis palabras y mi sangre" (Neruda, 2000, pp. 38-39). ${ }^{5}$ Porque ahí, en un corte que articula un modo de la voz propio de la poesía latinoamericana de los 60, la voz se vuelve homogénea, pasa por el verso y por la noción de canto y podría dividirse justamente en un reparto de las voces entre un arriba y un abajo aunque como reivindicación: "Sube conmigo, hermano". En Trilce, en cambio, la escucha de esa voz aparece siempre interceptada, sobre un fondo, o en medio de un sonido que no va hacia el logos, que no se conforma con el logos y por momentos es pura phoné.

Se trata de distintas posiciones, movimientos del ruido y el canto en la poesía. Porque ya Darío, en sus conocidas "Palabras liminares" a Prosas profanas (1978 [1896]) usaba las figuras contrapuestas del ruiseñor 
y "la gritería de trescientas ocas" (1978: 181). Se trataba, en ese caso, al menos de un planteo del conflicto entre lo escuchable, lo legible y lo que ingresa en tanto voz o escucha del poema, como separación tajante entre dos esferas, una claramente privada y otra referente a los nuevos públicos, a esa multitud que aparece como lectora y crítica, como intérprete de la poesía.

La poesía es, en realidad, el espacio de este conflicto, en el que la distribución de las voces y sus configuraciones se modula de formas diferentes. Porque no es lo mismo el griterío de Darío que el griterío/ la bulla de Vallejo. De hecho, el ruido en ese corte dariano del siglo XIX está tomando hegemonía (a la vez que el poeta va perdiendo su lugar en las sociedades burguesas) pero es lo que se distingue, con claridad, del discurso articulado o, mejor, de la palabra (poética, ciertamente). Darío, en esas "Palabras liminares" reparte dividiendo el reino de la naturaleza, ${ }^{6}$ aunque si vamos un poco más allá, el ruiseñor es el poeta (la tradición es larga, la inscripción de la figura no es de hecho modernista sino romántica e incluso clásica) y, entonces, la división estaría diseñada en términos de cultura y naturaleza. De este modo, la distinción se plantea entre los que tienen voz porque cantan y los que no la tienen. Aunque los que no tienen parte, en este hito histórico son tanto unos como otros: el poeta está dejando de tener una voz hegemónica (canta para los habitantes de su reino interior) y las ocas, aunque griten, están representando figuralmente a aquellos que comienzan a tener parte. Ese cerco se está derrumbando en ese punto, pero aún se mantienen con pulso férreo las fronteras. ${ }^{7}$ La gritería de las trescientas ocas (la individualidad del ruiseñor opuesta a la "multitud"), además, no parece indicar lo mismo, en cuanto al reparto de lo sensible, ni en tanto conflicto, que la "bulla" de Vallejo. Porque en este último caso, el ruido se constata pero no es lo que se puede separar de la palabra. A la vez, lo que viene a meter o intentar meter una cuña en el ruido tampoco es, como decíamos, la palabra racional aunque sí otro sonido a contrapelo de la tradición poética. Tal vez, en el caso de Trilce podría pensarse en un ruido que surge, con dificultad, en medio de otro porque incluso, si leemos el libro completo, esta distinción, esta escucha de un nuevo ruido, se produce sobre el tono íntimo de los poemas filiales. Lo lea quien lo lea, la prueba es irrefutable, cuando por ejemplo oímos "Al rebufar el socaire de cada carabela/ deshilada sin americanizar,/ ceden las estevas en espasmo de infortunio, / [...]/ Y la más aguda tiplisonancia/ se tonsura y apeálase” (1949, XXV, p. 103), en contrapunto con "Y nos levantaremos cuando se nos dé/ la gana, aunque mamá toda claror/ nos despierte con cantora/ y linda cólera materna./ Nosotros reiremos a hurtadillas de esto,/ mordiendo el canto de las tibias colchas/ de vicuña iy no me vayas a hacer cosas!" (1949, LII, p. 124). Incluso, los cuerpos que sostienen en los poemas estas dos lenguas, estos dos contextos de la voz se presentan de manera absolutamente distinta. En los primeros, se vislumbra un sujeto solo que por lo general parece gritar, amonestar o lamentarse. Es, además, un sujeto casi desasido del tiempo y el espacio. En los segundos, incluso cuando articulan el lamento amoroso, hay siempre un sujeto en relación a otro y envían por lo general al pasado y al paisaje de infancia.

\section{OÍD EL RUIDo / OÍD LA VOZ}

La poesía contemporánea articula muchas veces el poema como puesta en voz o performance. En estos casos, el sonido no es aquello inscripto en la letra, aunque se puede pensar en una interpretación vocal orientada a partir de un texto o un poema. En escena, también hay un reparto de la voz: no porque se trate de poetas o actrices leyendo/ recitando en voz alta sino porque la idea de resonancia se hace más fuerte. La resonancia, como dice Nancy puede definirse a partir de varias articulaciones: cuando se escucha un discurso o determinados signos, señales y lo que se atiende es el sentido más allá del sonido; cuando se escucha música y todo se cifra en el sonido. En realidad, agrega, "la escucha se dirige a -o es suscitada por- aquello donde el sonido y el sentido se mezclan y resuenan uno en otro o uno por otro" (2007, p. 9).

Cuando asistimos a una puesta en voz o a una performance hablamos, sin dudas, de este tipo de escucha. Sonido y sentido se solapan, de la misma forma que la voz está tensada o funciona en la zona de superposición entre logos yphoné(Dólar, 2007, p. 146). Qué hay entonces, del sentido en el sonido, y cómo suena ese sentido 
En noviembre de 2019 , en el curso del $16^{\circ}$ Festival Poesía de acá, que se lleva a cabo en la ciudad de Mar del Plata (Argentina), se presentó el dúo Marilú, compuesto por Mariano Balestena (músico) y Luciana Caamaño (poeta). ${ }^{8}$ Allí hicieron por primera vez una puesta que me parece pertinente traer a este análisis porque trabaja sobre el discurso político. ${ }^{9}$ En términos descriptivos aclaramos que Balestena manipula el sonido sobre un continuo sonoro que incluye marchas en distintos puntos de Europa, Estados Unidos o América Latina: hay un fondo que procede de grabaciones del estallido del 2001 en Argentina, el sonido de la movilización y la represión, el estallido social que provocó la declaración del estado de sitio en democracia, la renuncia del presidente Fernando de la Rúa, y dejó el saldo de 39 personas asesinadas. También son parte de este continuo registros del Mayo francés (1968); de una movilización en protesta contra la ley de censura de internet en Rusia (2019); de una reunión del Act up, previa a una movilización en los años de surgimiento del SIDA (1989); una marcha en Berlin, en contra de la guerra de Vietnam (1967); una marcha feminista argentina, o una marcha en Brasil contra Bolsonaro, ambas de los últimos años. El continuo, en realidad, lo produjo Balestena previamente, haciendo uso del corte y el loop, básicamente. En el momento de la performance dispara ese audio y trabaja texturas de la voz de Caamaño, generando incluso efectos, como la reverberancia. Luciana Caamaño arma un texto que en su voz, repite y corta algunos segmentos de dos discursos: el de Cristina Fernández de Kirchner el 9 de diciembre de 2015, en Plaza de Mayo, ${ }^{10}$ y el de Eva Perón en el día del trabajador, en la misma plaza, el 1 de mayo de 1952. ${ }^{11}$

Del discurso de Cristina Fernández de Kirchner que abre la performance toma en realidad segmentos mínimos, "Quiero decirles que", "Me hubiera encantado pero"; se trata de giros que se repiten en el discurso y que funcionan, en la puesta en escena de la performance de Marilú, como un anuncio de lo que se va a decir y prácticamente no se dice. Del discurso de Evita, en cambio, se toman fragmentos con potencia no sólo declarativa, o de advertencia ("Guay de ese día", "No ha pasado el peligro"), sino también fuertemente figurativos: "No lo conseguirán, como no ha conseguido jamás la envidia de los sapos acallar el canto de los ruiseñores, ni las víboras contener el vuelo de los cóndores". La continuidad inicial de los fragmentos hace que Evita diga aquello que Cristina Kirchner no dice en la performance: en esa continuidad, lo que se quiere decir es de manera saliente que el peligro persiste y a la vez se delimita un conflicto, una división de las voces a partir de un ellos (sapos, víboras) y un posible nosotros (ruiseñor, cóndor).

Comparada con su modulación de origen, la voz de Cristina Kirchner adquiere una leve puntuación irónica, en tanto se mantiene la altura tonal desafiante de Evita. Por supuesto que lo que se construye como partitura textual para la performance de Marilú se activa en la misma performance, en el acto de puesta en voz de Caamaño, en la repetición; pero también en la escena de la distribución de las voces y el ruido que arma su relación con el trabajo musical, sonoro de Balestena.

Pero además de la puntuación y el tono, lo que varía en la performance es la disposición de las voces. Cristina y Eva son, cuando pronuncian sus discursos en Plaza de Mayo, las que tienen la voz, y además hay un sonido que es el de la multitud que escucha y responde desde el llano de la plaza, como puede constatarse en los registros documentales. Lo que se despliega en estos casos es la racionalidad del diálogo político en el espacio público, en el que las partes tienen adjudicadas acciones, la de interpelación y respuesta en los cánticos, en el grito de alguna consigna. Así están distribuidas las voces en este caso, sin que signifique pasividad por parte del pueblo, ni ausencia de recepción de la que tiene la voz. En la performance de Marilú, en cambio, la voz de la que quiere decir o viene a decir algo entra en tensión, en una especie de pulseada por ganar la escucha, con el sonido de las manifestaciones. Por momentos no se entiende bien qué dice, pero tampoco se distinguen demasiado las voces de la manifestación, a tal punto que la secuencia del Mayo francés permitiría entonar, en un corto instante, algunos versos de la marcha peronista. Sin embargo, esta falta de claridad o indistinción es un índice común ya que esa masa de sonido de las manifestaciones, llevada a una altura máxima, con la textura que otorgan los sub graves, convirtiendo el sonido en una sensación táctil, como nos dijo Mariano Balestena en una charla, conecta con el volumen de la voz de Caamaño e incluso, con el tratamiento de reverberación que la saca del discurso político y la envía a la zona del rumor, la perfora. Porque cuando reverbera parece 
pegar contra la multitud de la revuelta y volver como un eco, contaminada. El uso del megáfono, incluso, debe leerse en esta línea en tanto técnicamente permite la amplificación de la voz, pero como dispositivo poético y político envía esa voz al interior de la multitud que se manifiesta. ${ }^{12}$ Porque en todo caso, lo que pone a funcionar la performance no es la articulación de un discurso político (ya cortado, además, convertido en pieza rítmica, en loop) sino el ruido que genera posiciones de la voz política alejadas de la idea de hablantes, de sujetos que tienen la voz y desde esa propiedad se relacionan con los otros. Lo que hay que escuchar, parece decir la performance de Marilú, es el ruido de la insurgencia, que discute el espacio con la voz autorizada de la política, para llevarla hacia el interior de ese sonido colectivo de los cuerpos en acción, en la calle. En este caso, la palabra política se da vuelta: el sentido resuena en ese sonido que funciona como contexto pero también como frontera.

Desde el año 1994 Cristina Banegas lleva a escena y dirige un unipersonal que retoma un poema de Leónidas Lamborghini, "Eva Perón en la hoguera”, incluido en el libro Partitas en 1972. ${ }^{13}$ El poema está dividido en XVIII partes y recupera, ajustado a la letra, La Razón de mi Vida (1952), un libro programático planteado como dispositivo autobiográfico, con un clivaje melodramático (Sillato, 1999; Cóccaro, 2012) y firmado por Eva Perón. Lo que hace sin embargo Lamborghini es cortar el texto de Eva hasta la exasperación, hasta las mínimas partículas (incluso aislando preposiciones o anulando sujetos y objetos): "brotado ha de los más íntimo. de mí a él:/ de mi razón. de mi vida./ lo que es un cóndor él hasta mí:/ un gorrión en una inmensa./ hasta mí; la más. una humilde en la bandada." (1972, I, p. 55). Lamborghini corta la frase de un texto en prosa; corta y repite. Algunas veces ese corte deja afuera significantes que tienen relevancia en $L a$ Razón de mi Vida. Porque en su poema nunca se nombra a Perón, pero sí aparecen sus sucedáneos, él, el cóndor, el líder. Entonces este corte podría pensarse como un borramiento o un solapamiento de los nombres propios; pero hay cortes más notables, como por ejemplo, en el poema VII, la rotación de términos que hace decir a Evita: "algo más. creo./ no: no digo Dios. perdóneseme./ fue: mi caso./ fue: mi vida. es. un destino. mi pueblo. una providencia./ un origen. mi país. creo. la presencia. mi alma." (Lamborghini, 1972, p. 62). Y en este caso, bajo ese corte, lo que se pierde es un "gracias a Dios", presente en La Razón de mi Vida. ${ }^{14}$ El trabajo sobre el texto radicaliza el discurso de Eva Perón y forma parte de lo que Dalmaroni analiza como descalabro de una sintaxis cultural (2002, p. 49).

Podría pensarse ese descalabro a partir de la voz, de la modulación que Cristina Banegas hace, una y otra vez (y de maneras diferentes) de esa voz inventada por Lamborghini para Eva Perón, de ese balbuceo, como lo caracterizaba él mismo. Una sintaxis, una distribución de la voz tensada por diversos tonos y también por otras voces o por el espacio común. Una voz que escucha, diría Peter Szendy.

¿Se escucha, en la puesta de Banegas esa voz inventada por Lamborghini? En principio Banegas articula el corte, no lo suaviza lo suficiente como para que la voz de Eva sea la de sus discursos públicos; el dramatismo del balbuceo aparece en escena, claramente. Sin embargo, lo que se escucha en la puesta de Banegas es la variedad tonal en un arco que va del susurro al grito, y el pasaje de esa variedad por el pulso emotivo que otorga diferentes texturas a la voz. No debemos olvidar, por supuesto, que el poema se convierte en una pieza teatral y, por lo tanto, la voz y el cuerpo estarán indisolublemente vinculados. Lo paradojal es que los tonos y sus variables habilitan diversas figuras de Eva y distintas posiciones de su voz: una podría incluirse en un círculo de intimidad, pero en otros segmentos, aparece amplificada y remite a la Evita de la plaza.

En la versión del poema VII de "Eva Perón en la hoguera" de 2012, ${ }^{15}$ aparece la muñeca: el gesto fijo, de pie con las manos levantadas y girando hacia un lado y hacia otro, en un semicírculo. Como una bailarina de cajita de música. Pero hay algo más, porque el giro delata la mecánica no orgánica del movimiento y los ojos clavados en el vacío, sin interpelar al espectador -sin hacer contacto-, también nos permitirían pensar en la figura del autómata. Hay un grado de artificio importante en esa puesta que uno podría asociar claramente a la propuesta de corte del poema de Lamborghini. Un movimiento cortado para el corte del discurso, un movimiento maquinal. Lo que trae esta decisión gestual es, además, el cuerpo de Eva (Banegas está, en esta ocasión, caracterizada a partir de la indumentaria y el rodete, como Evita); la posición de los brazos en varias 
de sus fotos y en muchos de sus discursos (como una retórica corporal de época tal vez). La autómata, la muñeca, sin embargo se va desarmando hacia el final del poema, porque e pesar de la inmovilidad del cuerpo, el grito parece interpelar a un oyente distinto. Entonces, esa voz ensimismada, que pareciera la de una Eva que ha quedado a lo largo de la historia desasida (en off), esa voz fantasmática vuelve a tomar contacto con los otros, con la política, retorna para demandar una escucha activa o para activar nuevamente la escucha política: de la explicación biográfica, "fue la causa" o "fue mi alma" a la ideológica, "fue:/ la injusticia siempre. por qué:/ pobres por qué./ ricos por qué” (Lamborghini, 1972, p. 62), el tono se desata.

En la versión del poema VII del año 2017, la voz de Evita/Banegas modula el susurro (por momentos pareciera que está diciendo un secreto) produciendo una suerte de espacio confesional: las dos veces que dice "hay que mirarlo", y el cierre del poema en el que, claramente, el tono baja y la voz se adelgaza (a la vez que el cuerpo se recoge sobre sí mismo). También la tenacidad de la voz que argumenta y arma una escena equiparable a la de un juicio (¿a quién le dice esta Eva/Banegas "perdóneseme"?), como si ella estuviese respondiendo ante un tribunal. ${ }^{16}$ Finalmente, el tono del discurso político en el espacio público, que se abre en el mismo momento que en la puesta de 2012. La diferencia con esta última es que la voz no es maquínica y las distintas modulaciones van acompañadas por una gestualidad que rearma la escena del discurso político (las manos apoyadas sobre la mesa, la mirada dirigida a los oyentes, el cuerpo que se alza y luego se repliega sobre sí mismo) enlazada con la del discurso íntimo, confesional, como si una y otra no pudiesen separarse.

Se trata del mismo poema de "Eva Perón en la hoguera" de Leónidas Lamborghini y lo que permite pensar es la apertura de la escucha cuando la voz sólo existe asociada a lo que se oye. La voz de Eva Perón, en Argentina, es una de las más salientes de la política y en la puesta de Banegas se abre a diversas escuchas.

En Escucha. Una historia del oído melómano, Peter Szendy desarrolla una teoría de la voz que retoma posturas filosóficas como las de Nancy e incluso Lacan y allí plantea una posibilidad de historizar la voz desde la escucha. La propuesta no se articula en relación con la literatura sino con la música, y más precisamente, a partir de la práctica del arreglo musical. El arreglista, dice, es el único que firma su escucha porque en el arreglo aparece una nueva apertura, la que hace audible el "original" ("como Schönberg orquestando a Bach, como Gould adaptando a Wagner al piano”: 2003, p. 23) y, simultáneamente, su propia escucha de ese original. Entonces, la escucha es, al menos, doble; se trata de lo que Szendy denomina "escucha bífida" (p. 54).

El arreglo se asocia, de este modo, a la idea de polifonía y a la de reescritura. Sobre la noción de reproducción aparece así la de producción, y esta abre un espaciamiento crítico; la escucha es polifónica, trae aparejada una plástica de la escucha que supone mutaciones, transformaciones tanto de las leyes de la escucha como de los sentidos de una pieza musical (Szendy, 2003, pp. 171-172).

A partir de Szendy podríamos pensar qué se escucha en la puesta de Banegas. Repetimos entonces, desde lo escénico permite escuchar el poema de Leónidas Lamborghini (de hecho, en las puestas del 2017 ella lee el poema, no se despega en ningún momento del papel: el texto ahí funciona como una partitura). Pero lo que aparece es el excedente sonoro, algo que no está en el texto de Lamborghini, o en su escucha imaginaria de Eva Perón. Porque uno podría ejecutar una lectura de ese poema con un tono monocorde, cortado pero monocorde. Y Banegas modula todo el tiempo ese corte, con altos y bajos, con cambios de tono. Consideramos que en la puesta de Banegas la voz de la Eva de Lamborghini se tensa con la voz real de Eva, la de sus discursos. Incluso cuando no está el cuerpo de Eva, cuando la actriz no está caracterizada como tal (como en el registro de 2017) aparece la voz pública. Porque Lamborghini dramatiza la escritura ensayística de La Razón de mi Vida, eliminando el fraseo argumentativo e incluso lo que hay de información sobre la vida de Eva Duarte en ese libro. Retoma, como dice Dalmaroni, la sobreactuación, el puro tono de ese texto (2002: 76), los momentos en que se advierte una cualidad performática, pero bajo el efecto de "la pura sintaxis partida” (p. 71). En la puesta de Banegas, en cambio, lo que aparece en primer plano es la figura del oyente; no sólo porque se trate (aunque no es un dato menor) de una escena teatral sino porque la Eva de Banegas modula al otro, imita la voz de Perón en el poema VI, cuando dice "los trabajadores: encárgate/ los descamisados: encárgate. encárgate", ${ }^{17}$ pero también abre el punto de audición: ${ }^{18}$ en el poema IX, "para 
mí los obreros:" se escucha una voz amplificada pero lejana, apagada a pesar del grito, como si escuchásemos a Eva/ Banegas desde la multitud de la plaza. ${ }^{19}$ Reponer la voz de Perón y sobre todo, reponer la instancia de la plaza, agrega una escucha, la de los discursos de Eva Perón, por ejemplo, la del discurso del renunciamiento a la candidatura a Vice Presidenta, el 31 de agosto de $1951 .^{20}$

Por otra parte, pueden escucharse prácticas concretas, como la de la declamación -duradera y de enorme trascendencia en Argentina, sobre todo a partir de Berta Singerman-. Una declamación de un texto (el poema de Lamborghini) que modula una gestualidad estructurada a la vez que trae de manera saliente el carácter fantasmático de la voz (Monteleone, 1997, pp. 232-234). También podría escucharse la incidencia de la radio en las voces políticas de época, esa de la que hablan Eliseo Verón y Silvia Sigal en Perón o muerte. Y aquí no habría que olvidar que Eva Duarte, antes de ser Evita era una de las voces del radioteatro argentino.

Abrir la escucha, abrirse en la escucha es lo que propone Szendy y es una premisa fundamental de la puesta de "Eva Perón en la hoguera" de Cristina Banegas. Esa escucha es crítica porque supone la reflexión, en el mismo momento que escuchamos, sobre la propia escucha. Banegas escucha el texto de Leónidas Lamborghini y a la vez, resuenan en su puesta en voz, los discursos de Eva Perón, y otras improntas históricas de la voz. Arma, de este modo, capas de escucha que no están necesariamente en el poema de Lamborghini y entonces, al balbuceo de Eva en ese poema, que es el balbuceo del peronismo proscripto en 1972, se suman los puntos de escucha de la multitud que resuena en distintos momentos históricos, el del kirchnerismo en 2012, pero también el del gobierno de Macri en 2017, entre otros. De tal modo que la voz de Eva se vuelve a escuchar como una voz política que abre una enunciación y ciertos tonos que se escucharán, a su vez, mediados por otras escuchas anteriores y en la encrucijada del presente.

\section{Puntuar la voz y La escucha}

Hemos advertido, al principio de este artículo, que no haríamos una lectura cronológica de la cuestión de la voz o lo escuchable en la poesía. Procedemos por saltos y estableciendo relaciones que nada tienen que ver con la influencia sino con cortes históricos, culturales que presentarían, a su vez, lo impuro de diferentes movimientos en relación con la escucha, con el oído de la poesía: así, José Martí ve y escucha la modernidad de una manera absolutamente diferente a Rubén Darío. Valga esto como nota que, sin embargo, no se desarrollará en este trabajo.

En "El Rey Burgués", uno de los cuentos de Azul (1888), Darío territorializa el reparto de lo sensible: el Poeta (así con mayúsculas) llega al castillo de ese Rey que ha perdido en cierto modo su aristocracia de sangre para imponer nuevas reglas a los haceres del poeta, bajo la pauta burguesa de la mercancía. En la visión deceptiva dariana, el poeta entra al palacio pero queda en una posición perimetral (el jardín) y desplazada, ya que su hacer se desfigura. Neruda abre otro trayecto que podría pensarse como punto saliente de estas configuraciones territoriales, sube a las ruinas de Macchu Picchu y también recorre imaginariamente todo el continente; Nicanor Parra sale a la calle y abre el oído incluso a lo que podría pensarse gráficamente -carteles, consignas políticas- mientras anuncia que "Los poetas bajaron del Olimpo" (Obra gruesa 1969); Enrique Lihn recorre el Paseo Ahumada de Santiago de Chile y presta oídos al mendigo, al roto.

Cuando Yanko González Cangas (Santiago de Chile, 1971) es interrogado por el origen de su primer libro, Metales pesados (1998), ${ }^{21}$ explicita su trabajo como antropólogo con "un cierto grupo de jóvenes urbano populares de un tiempo determinado, fines de la década de los 80'. Drogos, ideologizados tardíos, creativamente ociosos" de la capital chilena (Equipo Revista Matadero, 2000, s/n). Y también, inmediatamente, la disputa por un relato etnográfico por fuera del naturalismo y costumbrismo habitual en la disciplina. ${ }^{22}$

González Cangas, entonces, no recorre América sino que va hacia los márgenes de una ciudad con un objetivo concreto. No es, sin embargo, este tránsito el que más me interesa indagar sino aquello que la crítica 
describe en Metales pesados como las jergas, las estratificaciones de una lengua: lo que se escucha y de algún modo se escribe. Niall Binns piensa esa presencia, nuevamente en la encrucijada entre una poesía codificada en una lengua tradicional, una escritura y lo que sucede en Metales..., "la oxigenación de la poesía por el habla" (2016, p. 81). Y hay un diccionario que envía a estas hablas, efectivamente: "tunazos", "una fogueo pirateada" (González, 2016, p. 11); "fua/ perchó una parka asi”" (p. 13). Incluso, por momentos, una fonética: "quédate en mi calle/ comé con mi cusara/ sica/ viajera/ Qué buscas en sile/ en sipre/ en sillán" (p. 36).

Pero, nos parece interesante indagar un poco más esta idea de oxigenación de las hablas en relación con el reparto de lo sensible en Metales pesados, porque el aire es justamente lo que falta cuando el antropólogo ingresa a "El Triángulo" y boquea y tose: "BOQUIÉ en su centro y su maraña" (2016, p. 26), o bien: "me asfixiaron varias caras con un cable" (p. 66); y también en las referencias a las drogas, "Ya no tengo pulmón posible/ Y este pastilleo espeso" (p. 43), o bien "Afirmado en la música del trote/ me doy a la respiración artificial acompañado por un cono de papel higiénico" (p. 48). Aunque, más allá de estas referencias, el reparto de la voz, de las hablas podría pensarse en relación a la distribución de los cuerpos y los espacios. La voz, la escucha están asociadas de hecho a los cuerpos en términos orgánicos, a los pulmones pero también a la boca, a las encías: "Muerdo labio muerdo encía" (p. 17); "MORDÍA con molía/ babeo y cepo/ aquel lugar era la encía/ la ortiga/ la hostia fórmica/ adiós al polvo de los ángeles/ [....]/ PASAR al cuadrilátero/ a revivir los huesos/ carpo/ fémur/ húmero/ sacro/ tibia" (p. 34).

La entrada y la salida del Triángulo, en esta topografía geométrica que propone González Cangas involucra lo orgánico. Se sale, incluso, para recuperar los huesos. Y los cuerpos circulan por un territorio pautado por fronteras casi infranqueables, que podría leerse como el croquis de un laberinto, el que aparece por ejemplo en "La esquina de papito/ es efectivamente de papito" y las instrucciones que da en el poema para ubicar su parada:

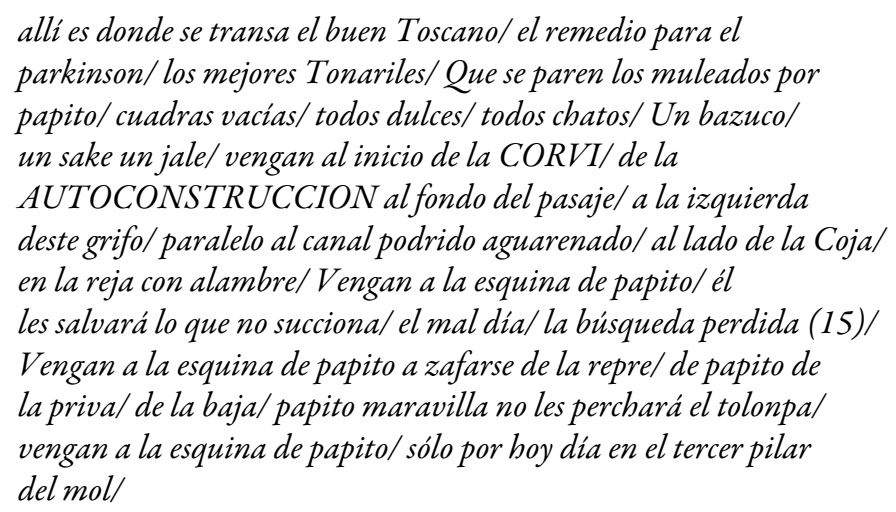

(15) “De todas las bestias salvajes, un muchacho es la más difícil de manejar" (Platón)*.

* "Platón es un pesado" (Nietzsche) (2016, p. 29).

Es esa división la que está escenifcada una y otra vez en la topografía de Metales pesados. La que produce la división de los cuerpos, los itinerarios posibles, el que inicia con la mención del estado (la CORVI chilena es la Coorporación de la vivienda) pero luego da indicaciones que parecieran funcionar sólo para los que habitan la zona (el grifo, el canal, la casa de la Coja, la reja con alambre). Lo que está afuera es el imperio, el mol. Y así como Papito ve ese afuera "con vitrina de neón" como el espacio del turista, hay imágenes en los poemas que, desde la mirada del antropólogo, envían a los habitantes del margen, irónicamente, al lugar de 
los salvajes: "Hubo aquí un tiempo de africanos/ donde los cabros comían cables telefónicos/ tenían un gran tejo de jeringa" (2016, p. 31); entonces "Viene el griterío/ se acercan Los Salinas/ están pinchando a todos con trece tenedores" (p. 41), "croan las tribus" (p. 38), "Intentan hacer caminos de caracoles/ por donde se van desfilando hacia/ La Berma" (p. 28), y cuando reducen "a fierrazos/ Al matón de la puerta/ Que se dice/ El Dueño de la Disco", "El ruido baja a los Depeche Mode" (p. 11). En eso que narran los poemas la división es insoslayable: cuando el antropólogo interroga, le contestan "nos balean tus preguntas" (p. 26), cuando los increpa "ELLOS CALLAN" (p. 38). Y a la vez, el periplo del libro abre la medida del fracaso pasándolo por lo que se puede ver y oír o decir: "fue que ya no escucho mudo" (p. 44), leemos entre una serie de argumentos sobre los obstáculos del antropólogo ("fue prohibido botar basura/ el Artículo 7 Orden de Aseo/ fue por qué no lo meten en un saco"); y luego: "Otros serán el busco mi destino/ los sujetos de mi observación participante/ la reconocida equivocación de mi ojo ciego", versos que llevan una nota al pie, la 25, que dice "ESTE PÁRPADO QUE DICE ADIÓS/ es el que llora/ mordiendo el ojo" (p. 51), superponiendo o más bien intercambiando las funciones de los órganos, desordenando un sensible porque ahora el ojo se conecta con la boca, muerde. ${ }^{23}$

La cuestión de las fronteras, del reparto desigual de lo sensible podría asociarse a otros límites, gráficos, de los poemas. ${ }^{24}$ Por ejemplo, las notas al pie, que arman un contrapunto de dos pisos en la página. Como si al laberinto topográfico (ese afuera) que es también laberinto de una lengua se lo explicase, se lo acotase siempre con citas irónicas, paródicas o sencillamente improductivas si se consideran como aclaración del poema. Porque ahí, en las notas, que reproducen traducciones del letrista brasileño Vilhena, o del poeta norteamericano William Carlos Williams, o de Francis Ponge pero también protocolos estatales sobre el consumo de drogas, funciona un desplazamiento, una elección muchas veces aleatoria; otras, en ese doble piso, aparecen poemas de esos jóvenes estudiados o del mismo poeta. El arriba y el abajo, de este modo, son móviles porque hay una lengua que cruza todo el dispositivo poético y deja afuera (aunque sea momentáneamente) a las otras.

Pero el mero uso de las notas al pie, como el uso de las comillas o de las palabras escritas en mayúsculas, en realidad (y aquí quería llegar) están puntuando una lengua. Y esa puntuación es la que permite que aparezca en esa división que se quiere férrea, algo de lo común. Sin que llegue a hacer sistema (o se transforme en un síntoma legible en un solo sentido) algunas palabras aparecen destacadas: PLACEBO, o en "El Triángulo", los verbos: "HUNDÍ en ese entonces dentro de su dentro este par de cueros leporinos/ que el isósceles lambisqueaba como hiena/ vesícula/ vejiga/ uréter/ vena iliaca/SAQUÉ/ sanándome/ leche de teta antes de la leche" (2016, p. 26). Estas últimas mayúsculas parecen en realidad remarcar acciones del que está en el Triángulo, "en su centro y su maraña" (p. 26), la zona de las tribus, autonominadas -"Los Pistols/ los Todos Por la Casa/ Los Cacho Cabra” (p. 15) - o reconocidas por sus nombres -los Chichi', los Beto', Los Chacalos, los Chinos/ Los Super-Bravos (p. 11) - para salir de una lengua y su pregnancia. De hecho, el poema que está en la nota al pie, la voz de uno de ellos, supuestamente, distinguido íntegramente por las comillas y firmado entre paréntesis (Chain), no se distingue demasiado de la del poema en la parte superior de la página, a no ser por la apelación que sitúa posiciones: "Es decir/ no me cuesta nada sacarte una lonja húmeda por Buzón Preguntón/ es decir no me cuesta nada enterrarte el tenedor/ Es decir nos tenís achacado/ Es decir nos balean tus preguntas" (p. 26). Todos estos signos, a pesar de ser impronunciables, son -diría Szendy leyendo a Derrida y a Nietszche- "golpes puntuantes" (2016, p. 95) que producen "diferencias de tono" (p. 94). Es el antropólogo, podría decirse en principio, el que puntúa, aísla y diferencia la voz de esos jóvenes marginales de la propia. Las primeras estarían siempre encerradas entre las comillas; la propia nunca. Puntuar es también cortar y en este caso, el corte sobre esa lengua del otro supone, obviamente, un cambio de contexto. En el orden más general de la escritura, las notas al pie puntúan los poemas. Sin embargo, y esto me parece lo más relevante, lo que está espacializado en la parte inferior de la página puede ser tanto la voz de otros los jóvenes pero también ciertos poetas o escritores, Gregory Corso, Verlaine, Plantón o Céline, cuya firma estaría encubierta por el nombre real, L. F. Destouches- como la propia. Es decir, que la voz de los otros se 
va moviendo en la página; y a este movimiento habría que agregar que tanto el corte de barreado (/), como el uso de las mayúsculas estarán tanto abajo como arriba y, sobre todo, marcarán tanto la voz de los otros como la propia.

En A fuerza de puntos, Peter Szendy aborda los signos de puntuación en sí mismos, pero también ciertos alertas sonoros en el cine o despuntes en la gráfica: los silencios, el pegoteo de las palabras (casi una constante de Metales pesados) y entonces, el modo de recuperar significados, de proponer sentidos de estas marcas. Pero habla también de una puntuación suplementaria, la que se encuentra en el gesto de sobrepuntuar; en realidad toda puntuación vuelve a puntuar, repiquetea, dice Szendy. Tal como la venimos describiendo, la puntuación en Metalespesados tiene que ver con la escucha, con la auscultación como modo de interrogar unos cuerpos, y de percutir un cuerpo sonoro, ${ }^{25}$ que es lo que hace Yanko González en el trabajo sobre esa lengua hacia la que va como antropólogo: no detecta allí un corpus informativo sino un corpus auditivo tramado por el grito, por la dicción, por la jerga, y por la velocidad. Además, lo que suena está, de hecho, percutido por ciertos ruidos o ciertas músicas. Está el fraseo del rap, la mención repetida del hardcore, el punk que aparecen en la repetición ("en el lote lote lote/ suenan radios radios radios/ echa el piso piso piso": 2016, p. 22) o en el golpe o el rasguido ("Los Hip-Hop recién escuchan/ El wurlitzer siempre tarrearon/ El compact o la doble cassetera/ Recién escuchan la aguja que ronca/ Entre los surcos”: p. 18). Y todo este corpus auditivo tiene un correlato en ciertas acciones/ figuras del libro: golpear, pincharse, jalar, succionar, vomitar.

Hay más de una puntuación, entonces, una sobrepuntuación definida por Szendy como gesto retrospectivo sobre aquello que ya está puntuado pero también en tanto "Sobre habla del movimiento de brinco que permite saltar de nivel, que hace pasar del plan del relato al del recitativo, de la historia a la manera de contar la historia" (2016, p. 176). Este es el significado que más nos interesa en relación a las políticas de la voz o las voces en general en la poesía, porque reenvía a un deber ser de la poesía que se ha instalado como signo de su distinción: la forma. Y consideramos que lo que hace Metales pesados de Yanko González es sobrepuntuar una lengua y que a la vez deja escuchar cómo esta sobrepuntúa la supuesta lengua de la poesía. Las comillas, en este sentido, no deben entenderse como marca comprobable del discurso del otro, porque de hecho, los poemas/ la poesía estará puntuada retrospectivamente por esta lengua. No importa decidir, y mucho menos aclarar, qué de las notas que toma el antropólogo en su trabajo de campo, o qué de las grabaciones, es textual/ testimonial. No importa el registro sino lo que ese registro hace posible. Una nueva partición de lo sensible, que es a la vez reparto de los cuerpos y los espacios: se escuchan los golpes, los pinchazos de esa lengua salvaje, no domesticada por el estado, por la institución, pero no se escuchan con un tímpano adocenado sino con uno perforado o que se deja perforar por los golpes:

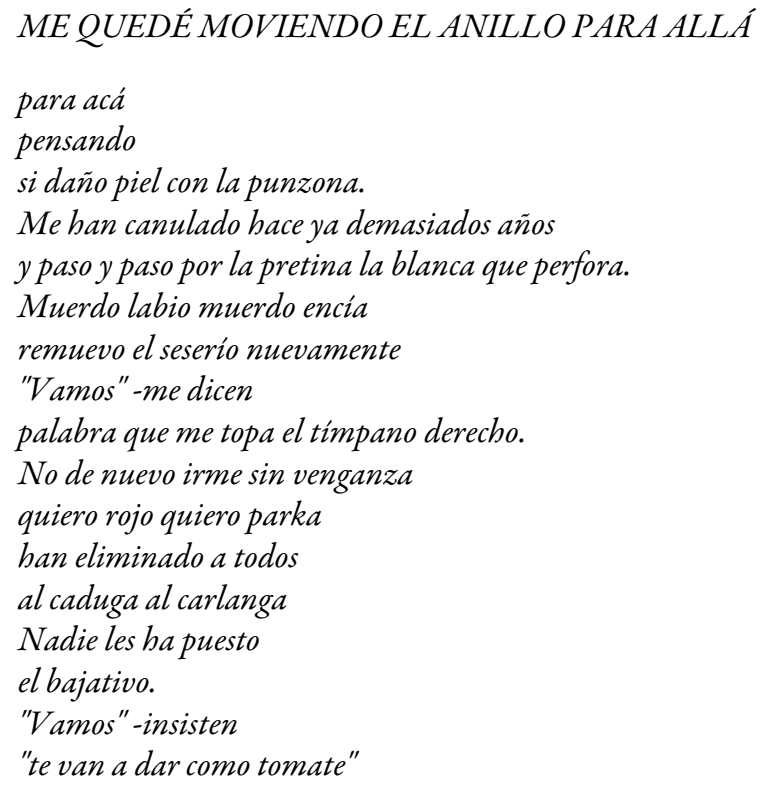




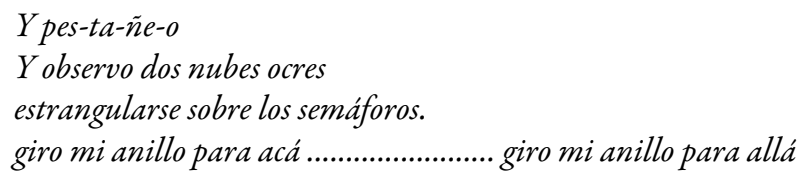

Fuente: El Auto parte (González, 2016, p. 17)

A quién le topa/ le golpea el oído derecho esa petición, esa orden ("vamos”). Quién muerde labio y encía y ha sido canulado hace tiempo. El que estaba afuera está adentro (o no puede salir), como se lee en otro de los poemas en el que los de la tribu o quien oficia de narrador en muchos de los poemas miran al antropólogo, "el precario traductor que aquí yace/ BUITREADO"; cuando "El LOGO se inyecta entre la tribu/ nada tiene que grabar/ sino su sombra/ nada tiene que mirar/ sino su ombligo/ el/ LOGO no usará el pretexto de la Observación Participante para chuparse todo/ La estrangulación de sus pulmones será hoy el tope" (2016, p. 52). Porque esa estrangulación de los pulmones, la falta de aire de una lengua nueva para la poesía (que es, en parte, la de unas hablas pero puntuadas, marcadas por el trabajo poético) tendrá que ver con la ubicuidad o el carácter pregnante de eso que pasa al poema. Lo que resuena en esa lengua, escuchada por Yanko González y llevada a la escritura es cierto carácter orgánico, ya que esta prolifera pero también se corta, avanza desenfrenada pero también se detiene, falla.

Dice Yanko González en una entrevista, ante la publicación de ese extraño libro suyo que es Elabunga (2011):

Estaba empeñado en escribir un libro multivocal y siempre dialógico, que continuara solfeando la lengua de lo que me interesa como sujeto y hablante, no sólo poético, sino también político: el poder cognitivo de la metáfora y su capacidad para herborizar e hiperbolizar el cómo las diferencias se transforman en desigualdades, ya sociales, ya culturales (Undurraga, $2011, \mathrm{~s} / \mathrm{n})$.

Solfear la lengua es una figura que envía, claro, a la música. Podría traducirse como reconocer (y a la vez leer/ ejecutar/ escuchar) una rítmica y una melodía; y en relación con las hablas trabajadas en Metalespesados, solfear una lengua supone estar atento a la puntuación, a los silencios. Esa lengua, además, está asociada a un habla que tiene carácter poético (la metáfora estaría siempre presente o la metáfora sería también lo que se hace con la lengua) y político. Solfear es, en definitiva, sobrepuntear en uno de los sentidos que le otorga Szendy, como "la hipérbole de una hiperpuntuación que, a fuerza de una articulación al por menor, atomiza, pulveriza, granula las frases y las formas" (2016, pp. 175-6). Entonces, lo que se pulveriza es la posibilidad de la fascinación costumbrista, así como el efecto de registro documental. Porque se sobrepuntúa para que allí aparezcan las desigualdades que la lengua impone y distribuye o reparte. La distinción queda a la vista: es una lengua marcada por la clase social, por la marginalidad y sin embargo, y esta es la piedra de toque en relación a la escucha, es la lengua que dará su imaginación figural y sus inflexiones al poema. Así, los poemas del narrador o el antropólogo estarán filtrados por ciertas inflexiones de los de los jóvenes (motes, parkas, cacho, puntazo, punzona). Los vasos comunicantes, el derrame para usar una figura más acertada por orgánica, es ya parte de la textura de los últimos poemas, en tanto el "Seppuku para Kawabata", poema que cierra el libro, calca a los drogos cuando se aconseja "calentar calostro en la cuchara poner la cuña" (González, 2016, p. 71) y la droga adquiere, además, la constitución de una pasta base de la poesía: "y sigue quie le sique/ con la funcia/ coun la funcia de la pasta/ la pasta/ la goma/ el ñoco du copete/ du poema que no para/ la funcia que me ampara/ la lojura" (p. 57).

\section{REFERENCIAS}

Binns, N. (2016). Non plus ultra: epílogo. En Y. González Cangas, Metales pesados (pp. 75-81). Santiago de Chile: Alquimia/ Montacerdos.

Cóccaro, V. (2012). La razón de mi vida y 'Eva Perón en la hoguera’: entre el relato y la voz. Babel, 26, 247-264. 
Dalmaroni, M. (2004). La palabra justa. Literatura, critica y memoria en la Argentina 1960-2002. Chile: Melusina. Darío, R. (1978). Poesía. Caracas: Ayacucho.

Dolar, M. (2007). Una voz y nada más. Buenos Aires: Manantial.

Equipo Revista Matadero (entrevista a Yanko González) (2000). Qué ves. Qué ves cuando me ves. Revista 101 Matadero, 1, s/n. Recuperado a partir de http://www.letras.mysite.com/yg211105.htm

Foffani, E. (2018). Vallejo y el dinero. Formas de la subjetividad en la poesía. Lima: Editorial Cátedra Vallejo.

García Helder, D. (1993). Introducción. En C. Vallejo, Trilce. Escalas melografiadas (pp. 10-28). Buenos Aires: Espasa Calpe.

González, Y. (2016 [1998]). Metales pesados. Santiago de Chile: Alquimia/ Montacerdos.

González, Y. (2007). Alto Volta 1998-2005. Valdivia: Ediciones El Kultrún.

Hoefler, W. (2001). Metales pesados: el centro marginal del lenguaje. Revista Logos, 10, s/n. Recuperado a partir de h ttp://www.letras.mysite.com/yg200205.htm

Lamborghini, L. (1972). Partitas. Buenos Aires: Corregidor.

Lihn, E. (1983). El Paseo Ahumada. Santiago de Chile: Ediciones Minga.

Monteleone, J. (1997). Voz en sombras: poesía y oralidad. Boletín del Centro de Estudios de Teoría y Crítica literaria, 7, 232-236.

Nancy, J-L. (2007). A la escucha. Buenos Aires: Amorrortu.

Neira, H. (2000). Anestética de Metales pesados de Yanko González Cangas. Revista de Estudios Filológicos, 35, 207-221. Recuperado a partir de http://www.letras.mysite.com/yg110505.htm

Neruda, P. (2000). Canto General. Alicante: Biblioteca Virtual Miguel de Cervantes.

Parra, N. (1983). Obra gruesa. Santiago de Chile: Andrés Bello.

Perón, Eva (1995). La Razón de Mi Vida. Buenos Aires: CSEdiciones.

Porrúa, A. (2001). Variaciones vanguardistas. La poética de Leónidas Lamborghini. Rosario: Beatriz Viterbo.

Porrúa, A. (2011). Caligrafía tonal. Ensayos sobre poesía. Buenos Aires: Entropía.

Porrúa, A. (2016). La voz impropia: poesía y política. Crítica Cultural, 11(2), 241-249. Recuperado a partir de http:/ /www.portaldeperiodicos.unisul.br/index.php/Critica_Cultural/article/view/4335

Quignard, P. (1996). Segundo tratado. Ocurre que las orejas no tienen párpados. En El odio a la música. Diez pequeños tratados (pp. 59-75). Santiago de Chile: Editorial Andrés Bello.

Rancière, J. (2009). El reparto de lo sensible. Estética y politica. Santiago de Chile: Lom ediciones.

Rancière, J. (2011). El destino de las imágenes. Buenos Aires: Prometeo.

Sigal, S. y Verón, E. (2010). Perón o muerte. Los fundamentos discursivos del fenómeno peronista. Buenos Aires: Eudeba.

Sillato, M. del C. (1999). La razón de mi vida de Eva Perón: el texto como espacio de auto-representación melodramática. Canadian Journal of Latin American and Caribbean Studies, 24(48), 177-193.

Szendy, P. (2003). Escucha. Una historia del oido melómano. Buenos Aires: Paidós.

Szendy, P. (2015). En lo profundo de un oído. Una estética de la escucha. Santiago de Chile: Metales pesados.

Szendy, P. (2016). A fuerza de puntos. La experiencia como puntuación. Santiago de Chile: Metales pesados.

Undurraga, V. (entrevista a Yanko González) (2011). No creo en la cobardía veloz de la pistola, sino en la valentía parsimoniosa de la soga. The Clinic. Recuperado a partir de http://letras.mysite.com/yg201011.html

Vallejo, C. (1949). Poesías completas (1918 - 1938). Buenos Aires: Losada.

\section{Notas}

1 La idea de distribución de las voces se inicia asociada a la noción ranciereana de "reparto de lo sensible", definido como "ese sistema de evidencias sensibles que permiten ver al mismo tiempo la existencia de un común y los recortes que definen sus lugares y partes respectivas. Un reparto de lo sensible fija entonces, al mismo tiempo, un común repartido 
y partes exclusivas. Esa repartición de partes y de lugares se funda en un reparto de espacios, de tiempos y de formas de actividad que determina la manera misma en que un común se ofrece a la participación y donde los unos y los otros tienen parte en ese reparto" (Rancière, 2009, p.9).

2 Este trabajo se articula como tres ensayos críticos sobre la voz y la escucha, circunscriptos por distintos corpus. En filigrana, o de manera implícita, las resoluciones analizadas que se enlazan a partir de nociones teóricas entrarán en diálogo, marcarán distintas posiciones históricas ante los mismos problemas. Es por esta razón que no previmos un tramo conclusivo sino una instancia de revisión de ciertas posturas de la crítica específica y de presupuestos desde los cuales se han analizado habitualmente estos autores/ poemas, o incluso cuestiones como las de la relación entre oralidad y escritura en la poesía.

3 Daniel García Helder propone una lectura absolutamente diversa de Trilce, destacando la alternancia entre los poemas más experimentales y los más “clásicos" en el libro. Estos últimos, los familiares, agrega, entran en relación y generan una continuidad con los primeros poemas de Vallejo, los de Los heraldos negros (1919). (1993, pp. 10-18)

4 Enrique Foffani piensa en las voces de Trilce, en su polifonía y en su funcionamiento, como sedimento de una memoria en peligro que aflora en los poemas; piensa allí "una lengua que se desterritorializa" a partir del shock profundo que supone la experiencia de la modernidad en Lima, y "se desmadra” porque es el resultado de la pérdida de la lengua materna (Foffani, 2018, pp. 244-245).

5 He analizado la voz política de la poesía de Pablo Neruda en "La voz impropia. Poesía y política” (2016). En este artículo se puede leer un desarrollo más amplio de esta figura de dar la voz a la historia, a los oprimidos como gesto de apropiación que resulta, a su vez, una expropiación y una conversión de la palabra del otro en canto, en poema.

6 Leemos en uno de los fragmentos de "Palabras liminares": "La gritería de trescientas ocas, no te impedirá, silvano, tocar tu encantadora flauta, con tal de que tu amigo el ruiseñor esté contento de tu melodía. Cuando él no esté para escucharte, cierra los ojos y toca para los habitantes de tu reino interior. ¡ Oh pueblo de desnudas ninfas, de rosadas reinas, de amorosas diosas!" (Darío, 1978, p. 181).

7 Un análisis de este proceso en relación con la autonomía o la heteronomía del campo literario latinoamericano, y la elección política del esteticismo dariano de dividir las voces, puede leerse en Porrúa (2011, pp. 23-64).

8 Algunos de los libros de poesía de Luciana Caamaño (Mar del Plata, 1983) son: cocorita (Mar del Plata, dársena3, 2006); Desatinada: soberana del mambo (Formosa, Nasaindy cartonera, 2010); No le digas que murió Chabrol! (Buenos Aires, Spyral Jetty, 2011); Los grados del escándalo (Mar del Plata, Sacate el saquito, 2013); Plan bestia (Rosario, Neutrinos, 2015), Acá no (Cáceres, Ediciones Liliputienses, 2016) y Lugares comunes de la lengua (Buenos Aires, n ediciones, 2018). Mariano Balestena es un productor musical y músico electrónico nacido en Mar del Plata (1992). Forma parte de varios proyectos en los que confluyen la música electrónica y experimentación tímbrica, como el dúo Prisma o DEEPFAKE, su proyecto solista.

9 El registro audiovisual y el continuo sonoro de las manifestaciones (un trabajo de producción de Mariano Balestena) que ingresa como pieza fundamental junto a la voz de Luciana Caamaño a la performance se pueden ver y escuchar en la entrada "Marilú" de la sección "Archivo / Materiales" de Caja de resonancia. https://cajaderesonancia.com/index.p hp? $\bmod =$ archivo-materiales\&view $=$ detalle\&id $=511$

10 El discurso de Cristina Fernández de Kirchner al dejar la presidencia puede verse y escucharse aquí: https://www.you tube.com/watch?v=o8GfcrmpIBY

11 El discurso de Eva Duarte de Perón puede escucharse aquí: https://www.youtube.com/watch?v=Z7eqcfY9138

12 Es relevante destacar, más allá de las descripciones ya realizadas de los segmentos del continuo sonoro, que se trata de un sonido localizado en distintos puntos del mundo e intermitente en lo cualitativo, ya que puede aparecer en una marcha feminista o en una de derechos humanos, incluso en el mismo país, y en términos temporales. El continuo se escucha como una unidad, exhibe en todo caso las modulaciones rítmicas y tonales de esa unidad. Es la voz de la insurgencia, la protesta, la revuelta callejera en un arco que va del Mayo francés al Brasil de Bolsonaro. En este punto podríamos decir que no importa tanto lo que se dice, se canta o se grita en esas movilizaciones sino el tipo de sonido que generan o que las constituye.

13 Salvo la puesta de 1994, en el auditorio de la librería Gandhi de Buenos Aires que estuvo dirigida por la bailarina y coreógrafa Iris Scaccheri.

14 Ver el análisis de las operaciones de Leónidas Lamborghini sobre La Razón de mi Vida, en Variaciones vanguardistas. Ver pp. 161-171

15 Los videos a los que haremos referencia en este trabajo se encuentran en Caja de resonancia. Ver http://www.cajaderes onancia.com/index.php? $\bmod =$ archivo-materiales\&view $=$ detalle\&id $=512$

16 Destacamos en esta línea la articulación de los poemas VIII y el X de Leónidas Lamborghini (páginas 62-3 y 64 respectivamente) en la puesta de Banegas, en los que la voz está, claramente respondiendo con vehemencia, dando argumentos a la vez que increpa a ese oyente que se diseña como opositor. Pueden escucharse en la versión completa de la puesta de "Eva Perón en la hoguera" de 2017, en el mismo link, http://www.cajaderesonancia.com/index.php?mod= archivo-materiales\&view=detalle\&id=512, a partir de 5' 38” (poema VIII) y de 8' 49” (poema X). 
17 Puede escucharse en la versión completa de la puesta de "Eva Perón en la hoguera" de 2017, en el mismo link, http://w ww.cajaderesonancia.com/index.php?mod=archivo-materiales\&view=detalle\&id=512, a partir del minuto 2' 38”.

18 En este sentido, consideramos que la puesta de Banegas desmiente o al menos entra en conflicto con la posición de Quignard (más cercana, con certeza, a la puesta ya analizada del dúo Marilú): "Lo que es oído no conoce párpados ni tabiques ni tapicerías ni murallas. Indelimitable, nadie puede protegerse de él. No hay un punto de vista sonoro. No hay terraza, ventana, torreón, ciudadela, mirador panorámico para el sonido. No hay sujeto ni objeto de la audición. El sonido se precipita. Es el violador." (Quignard, 1996, p. 60)

19 En la misma versión completa de la puesta de 2017, a partir de 6' 28".

20 El discurso puede verse y escucharse en https://www.youtube.com/watch?v=ayRWr1K0Mew

21 La primera edición de Metales pesadoses de 1998 y se publicó en Valdivia por Ediciones Kultrún. Nosotros manejaremos una edición de 2016 que respeta el texto original hasta en el formato del libro.

22 La crítica ha relacionado Metalespesados (1998), su primer libro, con su trabajo de antropólogo, más precisamente con el trabajo de campo. Allí, entonces, el poema se solaparía con el documento, con el registro (más o menos científico) de las voces de jóvenes marginales. Y ciertamente hay una antropología de la lengua, una etnografía, en los poemas de Yanko González que hace de los rasgos de la oralidad su objeto. Dice Hernán Neira: "Metales pesados [...] está centrada en las tribus de jóvenes marginales urbanos, a los que describe de modo hiperrealista", "situándose al centro de la polémica platónica relativa al lugar del poeta dentro de la polis, o quizás la tribu, de los etnógrafos rodeados por la marginalidad urbana siendo ellos marginales en la epistemología de las ciencias posmodernas [...] Opone la anestética de lo marginal a la estética de lo bello" (2000, s/n). Y Walter Hoefler: "Sospechamos que se trata de un programa de etnopoesía (dado el epígrafe de Evans-Pritchard que abre Metales pesados), como "un viaje al centro marginal del lenguaje" (2001, s/n).

23 Hay momentos en que la voz de uno y otros se diferencia más, pero se trata de intermitencias que arman dos lenguas sordas entre sí, que no podrían escucharse. Transcribo dos citas para ejemplificar, ambas funcionan como notas al pie:

"14) 'Sí/ es cierto que nos rascamos el paquete en la pura esquina/ pero para qué andar gritando/ para qué picarla de engomado/ tú anduviste igual/ ¿qué de las 3 de la tarde en adelante?/ puro echarte en la solera/ entonces/ para qué funar esta movía/ para qué funarnos/ para qué picarla de aahh/somos los más locos/ a todo hendrix/ no pasa/ a h í n o m a i s/ para qué cartelear a tus sociates/ qué/ te dan monedas/te mueven motes/ te caen mejores zorras/ el lafurcade regala tu libro en cuánto vale el chou?' (Mediano)” (2016, p. 28)

24) “Tanto hablaron de lo drogo que estaba el yimy/ que intenté/ para mi capote/ elaborar un par de hipótesis/ del orden de la investigación positivista/ experimental/ Cuando muchos decían el reviente/ el estado hecho tira que se encontraba/ expuse: Cuál es la influencia del Zipeprol en la caída del pelo de Jaime Meléndez/ como variable independiente/ obviamente el Zipeprol que puede ser suplantado/ por orégano/ chamico/ por películas de Columbo/ por esta comunicación personal/ o por esta observación muchas veces discutida/ entre nosotros/ científicos del reviente/ en la estación experimental de Galvarino Ponce." (2016, p. 43)

24 Rancière piensa en la distribución de las palabras en la página como "divisiones del espacio común”, como definición de "ciertas configuraciones de lo visible y lo pensable, ciertas formas de habitar el mundo sensible" (2011, p. 103)

25 Szendy recupera la figura de la auscultación médica para pensar en la escucha filosófica y dice: "aquél que ausculta el cuerpo lo penetra, incluso lo perfora, lo marca y lo detalla en cuanto corpus auditivo. Y lo hace planteando preguntas a esa cavidad hueca" (2015, p. 64). 